ISSN (Print): 2709-9636 | ISSN (Online): 2709-9644

Volume 2, 2021(Issue III, July to September)

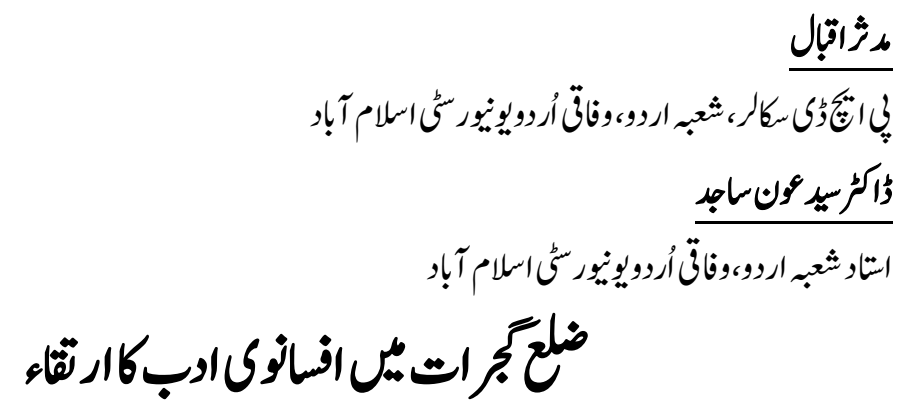

Mudassar Iqbal

Ph.D Scholar, Department of Urdu, Federal Urdu University, Islamabad.

Dr. Syed Aoun Sajjid

Department of Urdu, Federal Urdu University, Islamabad.

\title{
The Tradition of Legendary Literature in Gujrat District in the Twentieth Century
}

In literature, District Gujrat has its own individuality. Many renowned personalities took birth in this area of Greek. The most prominent figures among these are Abdullah Hussain and Anwer Masood. With above mentioned personalities, there are also many other literary personalities like Deputy Nazir Ahmed Dhelvi, and Syed Abid Ali who belong to this particular area. I have spent much of my time in this area. According to my experience, Gujrat could not maintain his own individuality as a literary center because Lahore and Rawalpindi took its literary figures in their laps. Some resided in big cities to seek their means of earning. Those who remained were waiting for their luck to shine. Lahore holds an important place with special reference to literature that is why literary activities have always been at peak there. Many movements took birth there, which had revolutionized the literary field, much research has been done on these organizations but despite being a rich literary place, Gujrat could never get this credit of being a prominent place from the literary point of view.

Key Words: A6dullah Hussain, Nadar Log, Saif ur Rehman Safi, Khita Yunaan, Prof. Zuhair Kunjahi, Navel, Afsana, Shoaib Sadiq, Sang e Mar Mar. 
ISSN (Print): 2709-9636 | ISSN (Online): 2709-9644

Volume 2, 2021(Issue III, July to September)

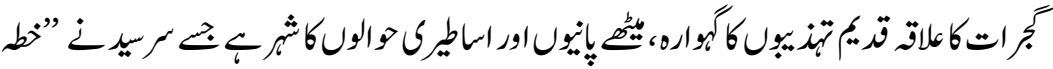

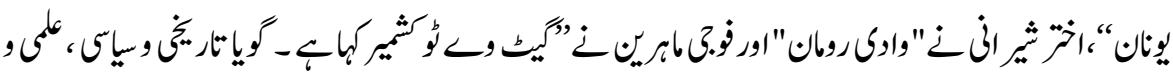

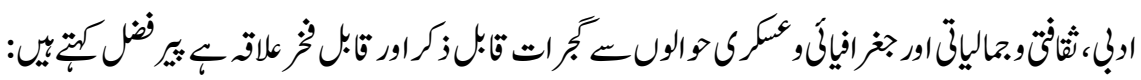

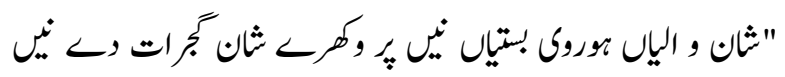

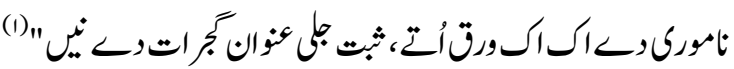

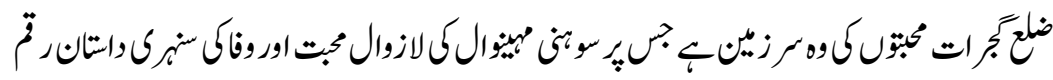

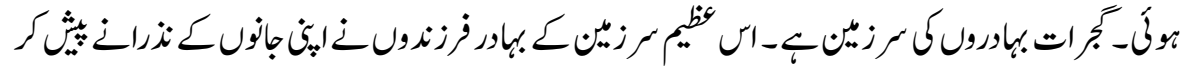

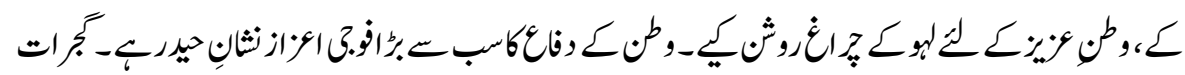

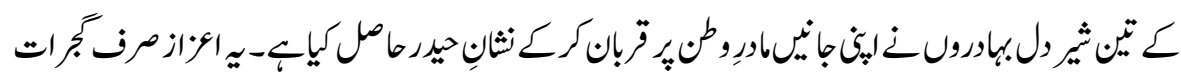

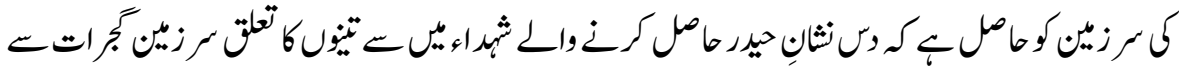

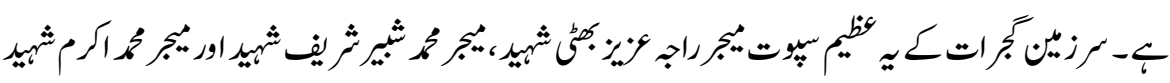

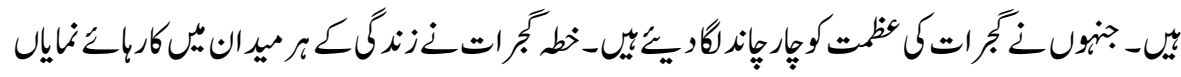

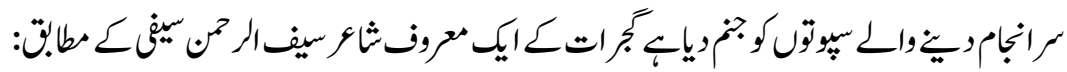

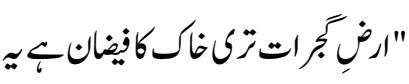

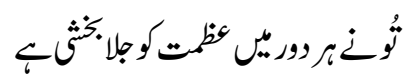

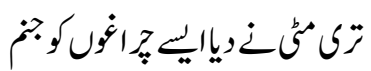

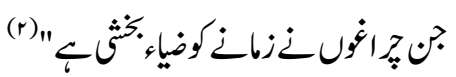

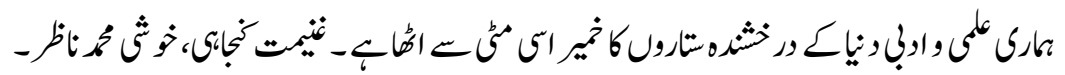

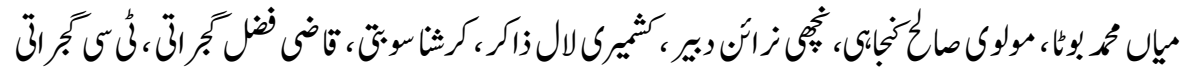

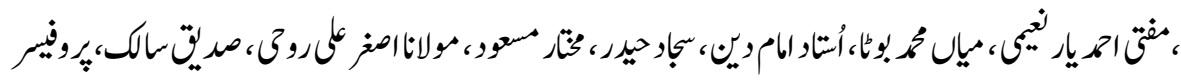

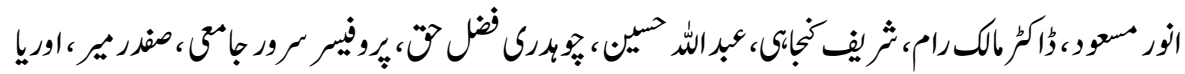

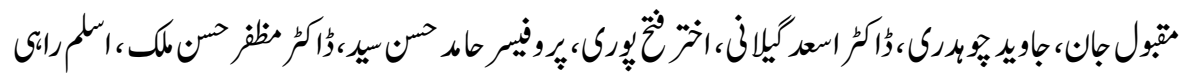

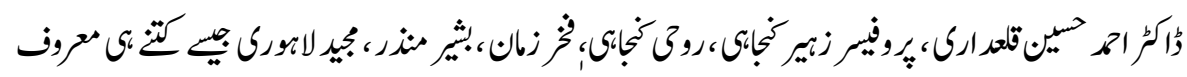


ISSN (Print): 2709-9636 | ISSN (Online): 2709-9644

Volume 2, 2021(Issue III, July to September)

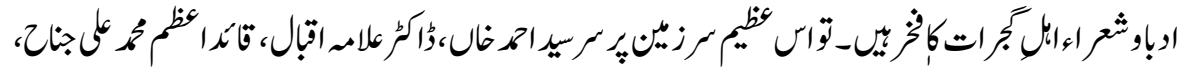

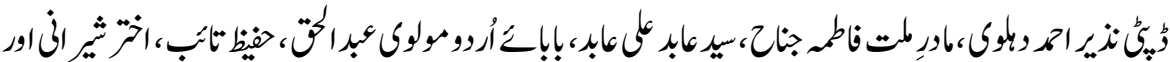

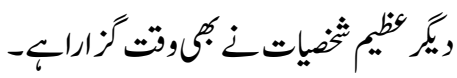

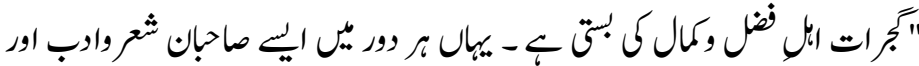

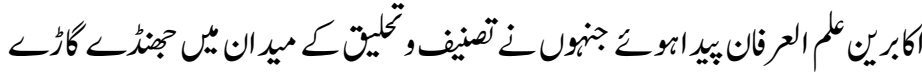

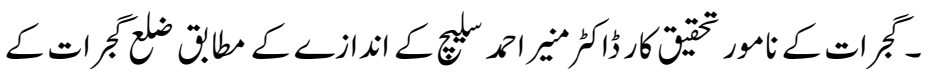

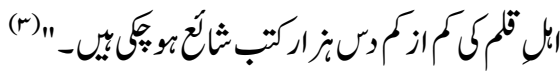

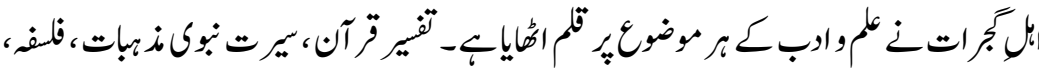

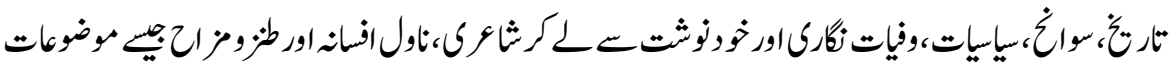

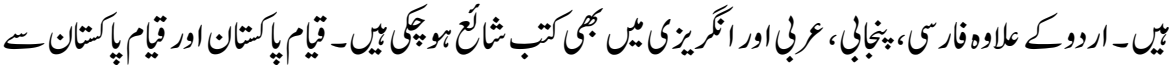

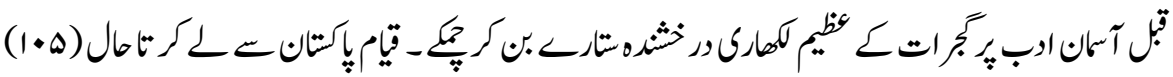

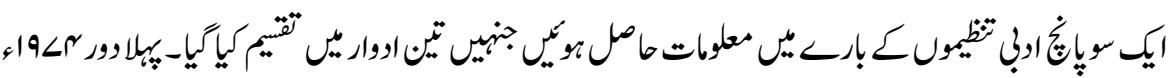

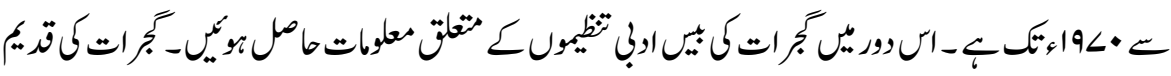

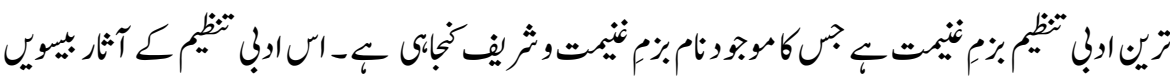

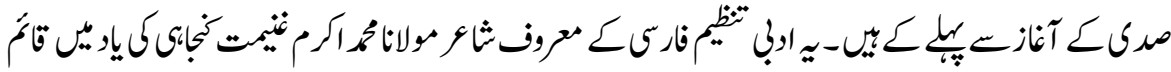

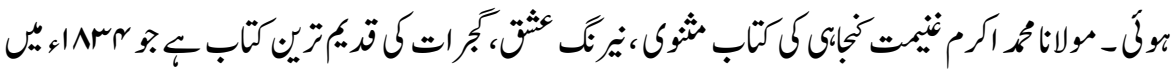

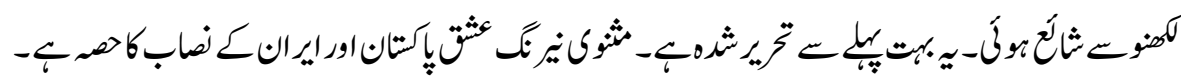

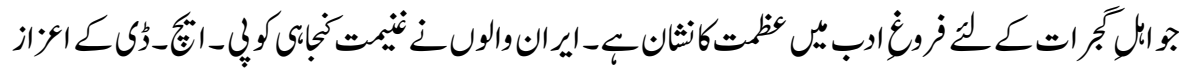

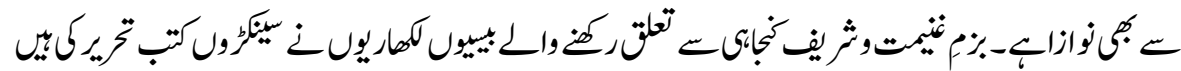

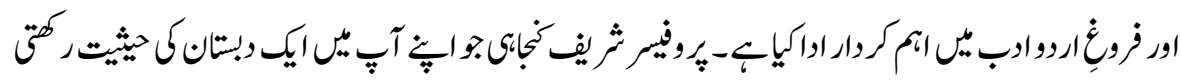

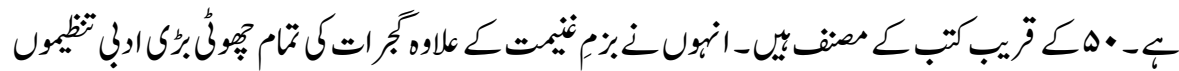

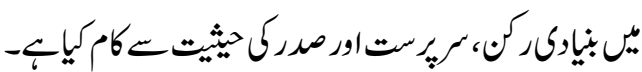


ISSN (Print): 2709-9636 | ISSN (Online): 2709-9644

Volume 2, 2021(Issue III, July to September)

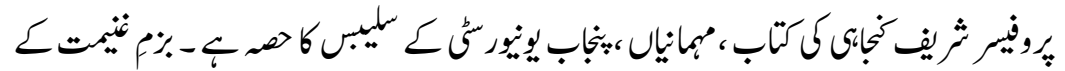

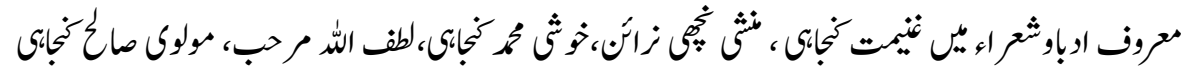

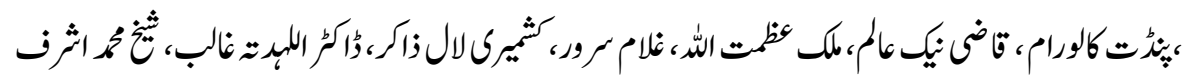

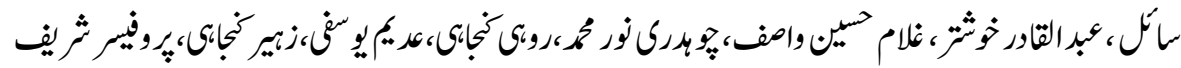

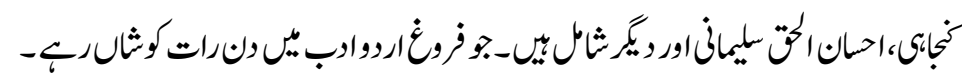

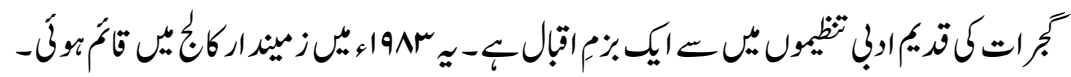

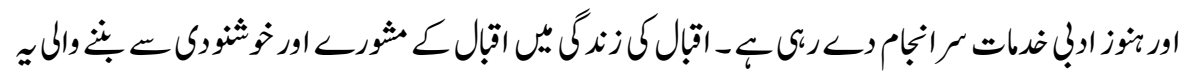

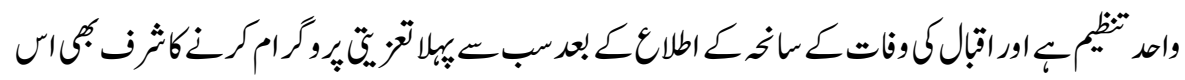

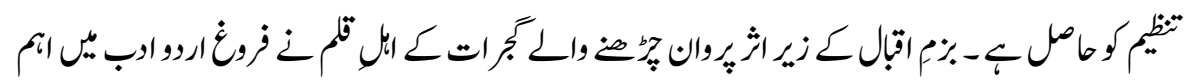

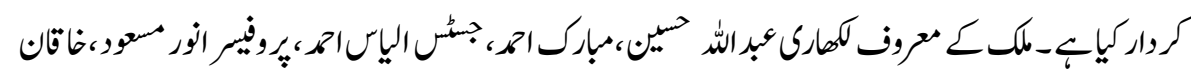

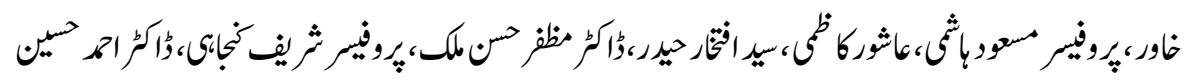

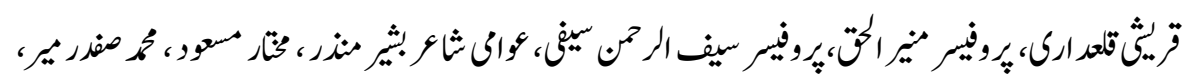

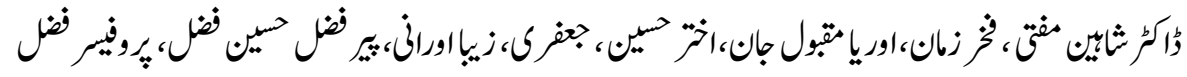

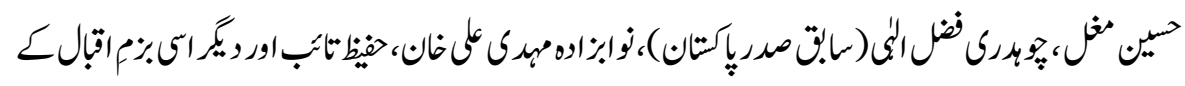
كرورنهי.

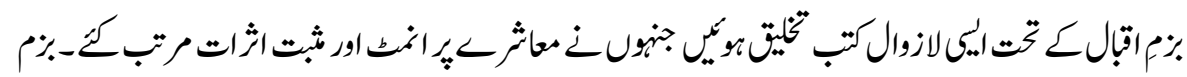

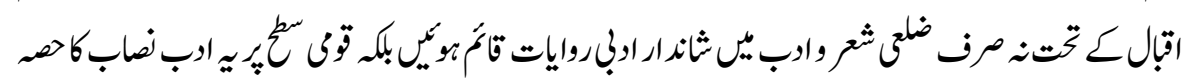

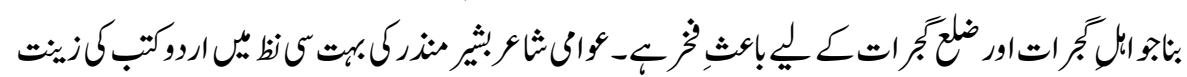

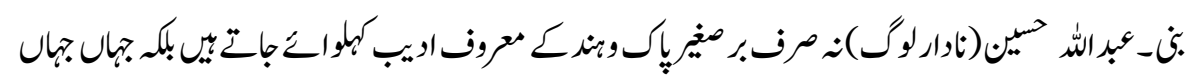

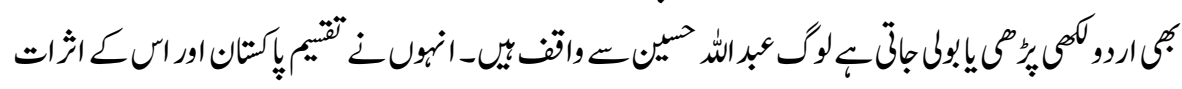

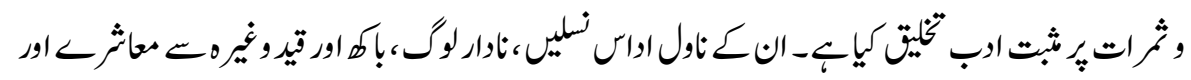

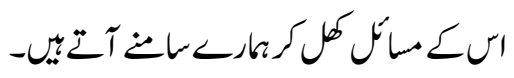


ISSN (Print): 2709-9636 | ISSN (Online): 2709-9644

Volume 2, 2021(Issue III, July to September)

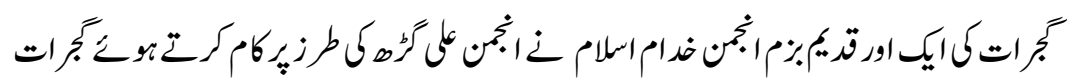

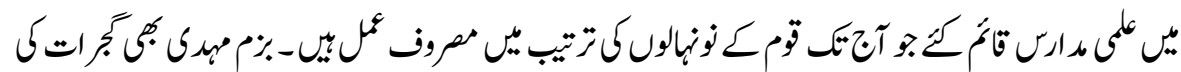

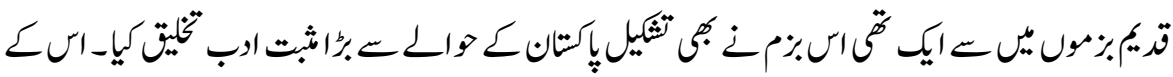

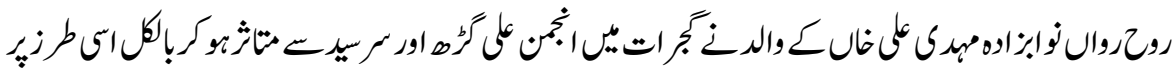

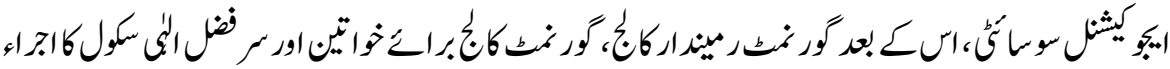

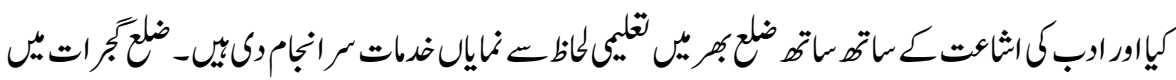

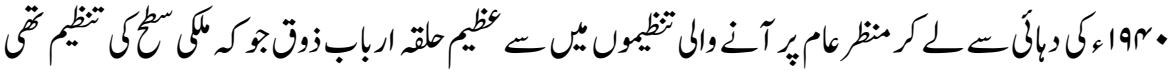

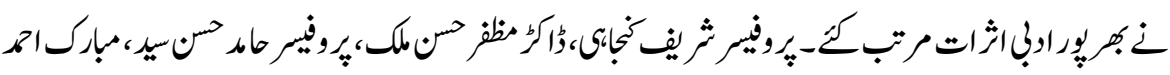

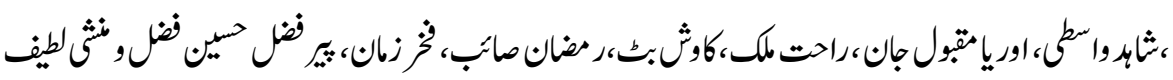

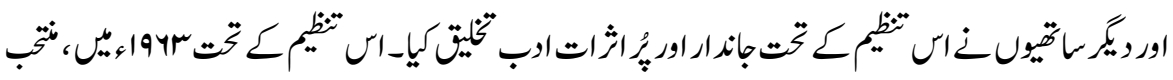

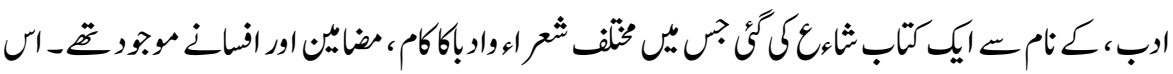

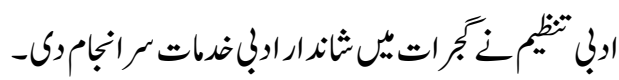

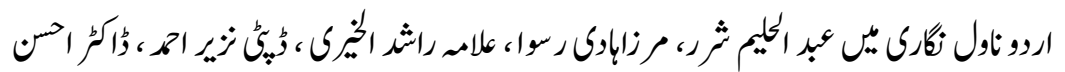

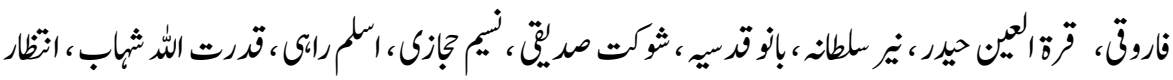

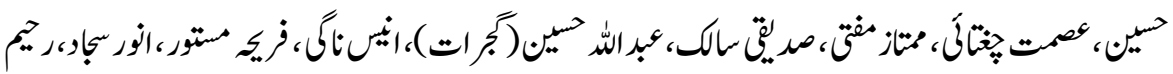

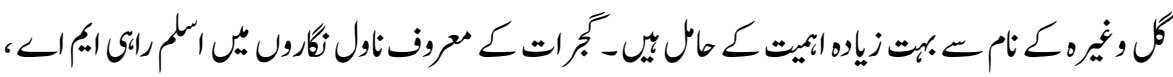

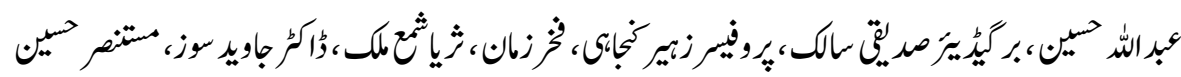

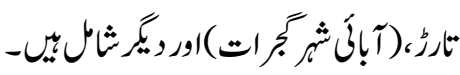

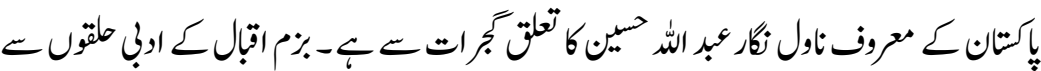

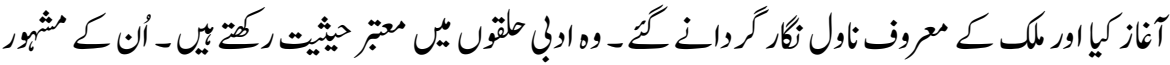

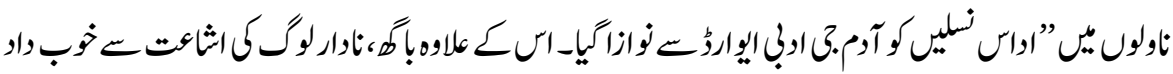

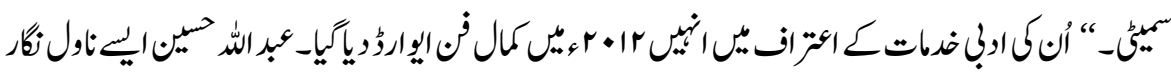

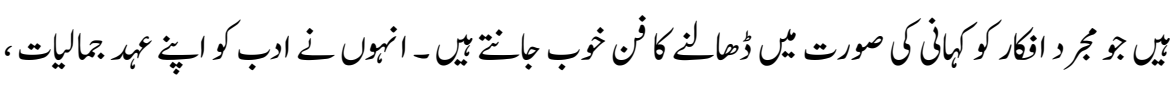




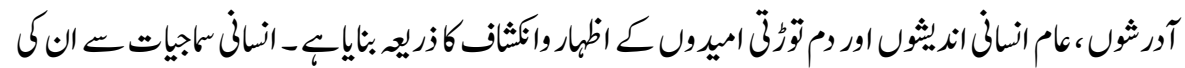

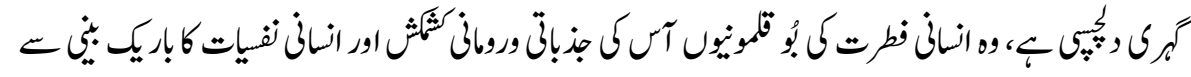

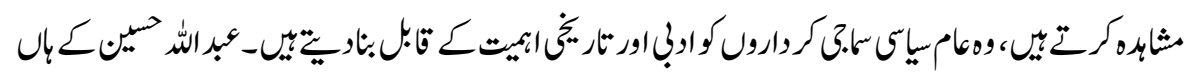

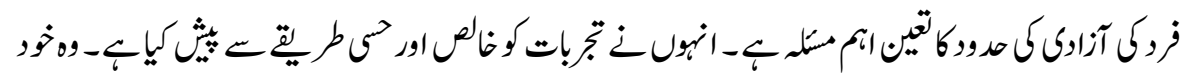

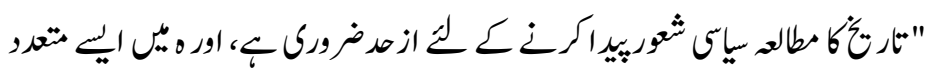

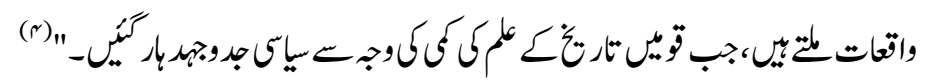

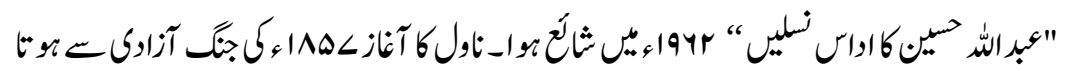

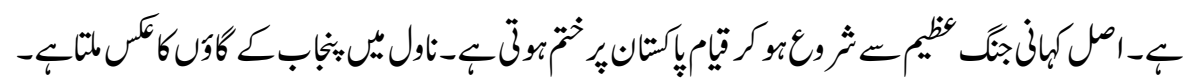

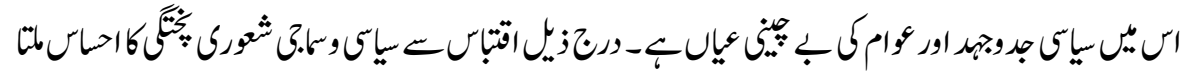

(4)

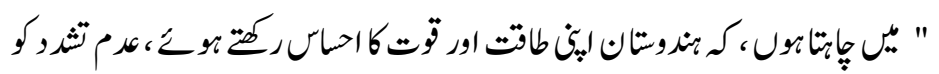

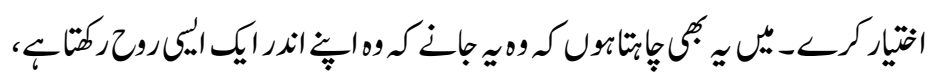

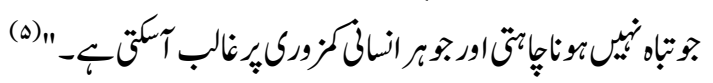

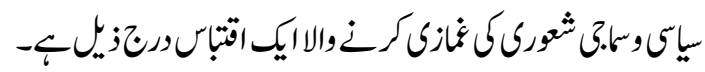

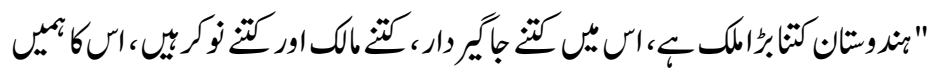

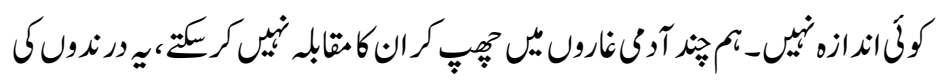

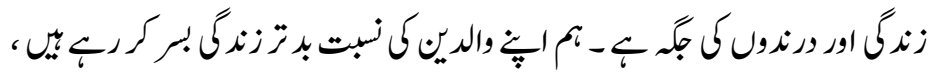

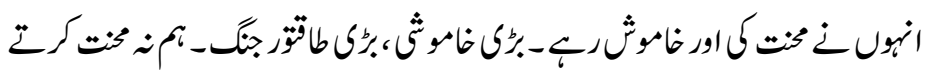

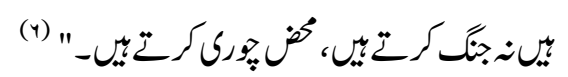

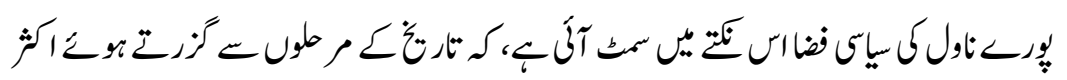

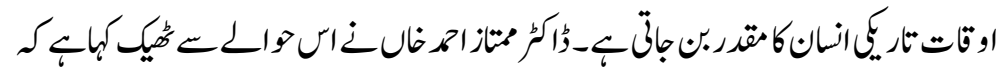




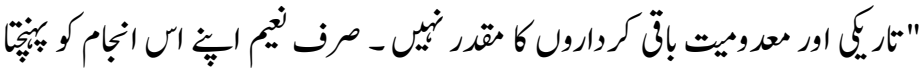

(L) ,

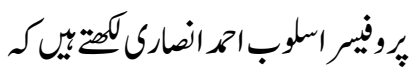

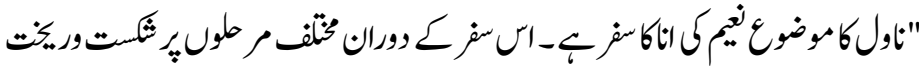

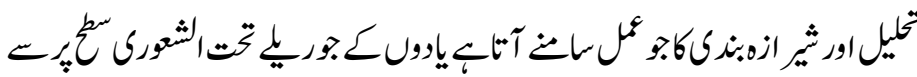

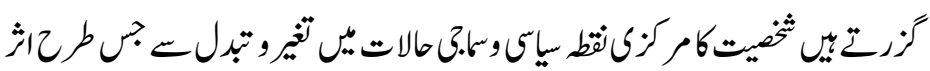

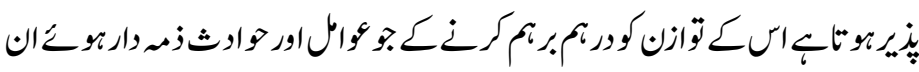

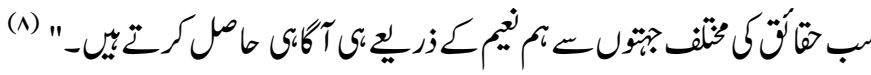

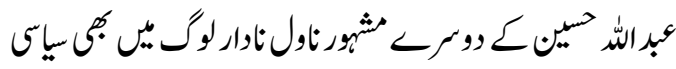

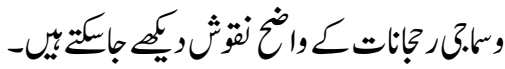

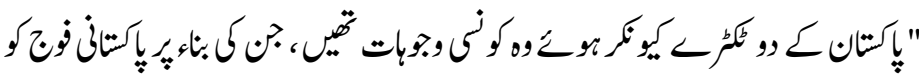

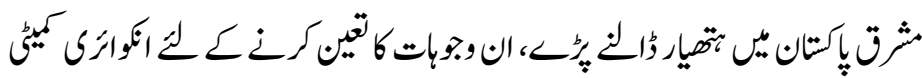

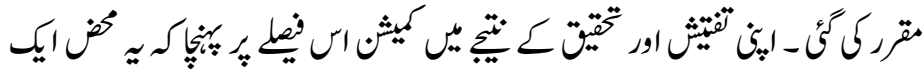

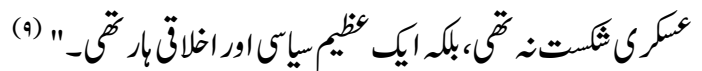

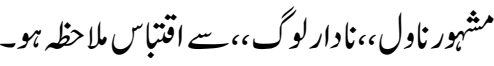

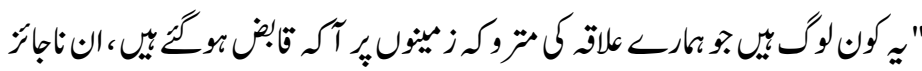

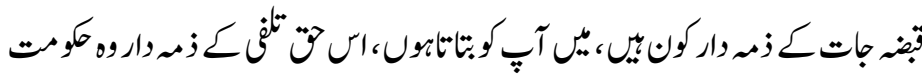

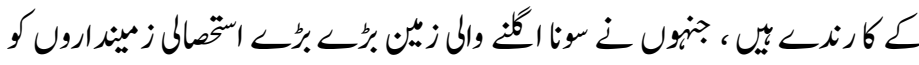

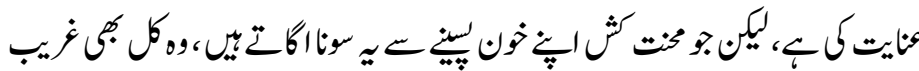

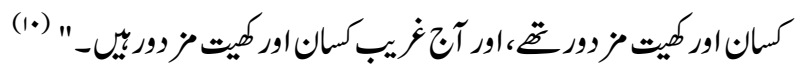

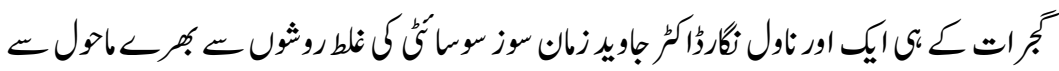

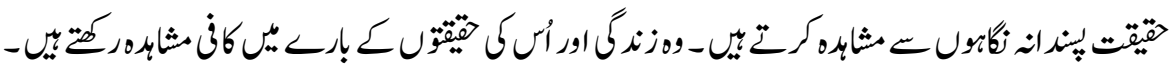

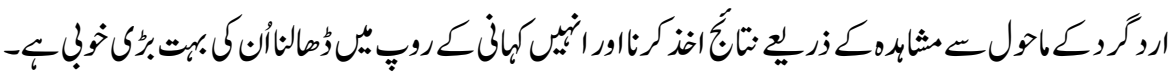


ISSN (Print): 2709-9636 | ISSN (Online): 2709-9644

اخز تِقيق مجلح

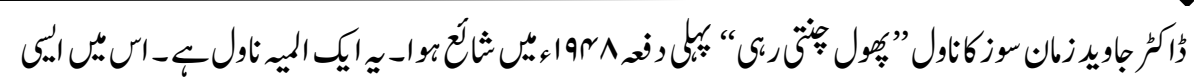

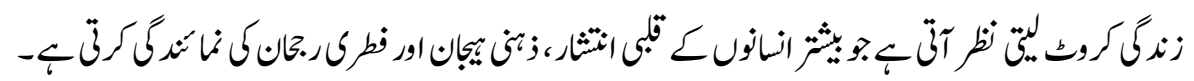

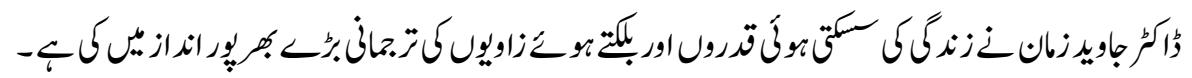

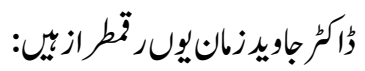

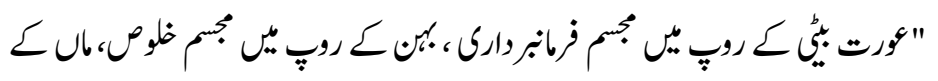

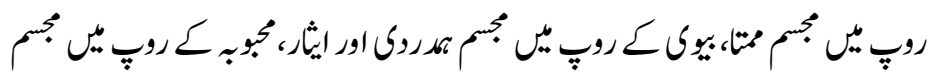

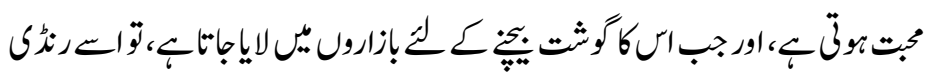

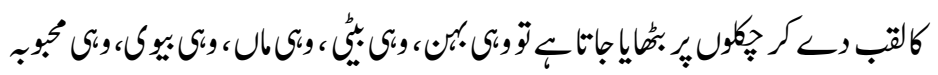

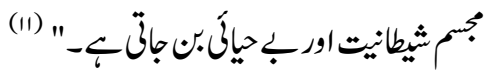

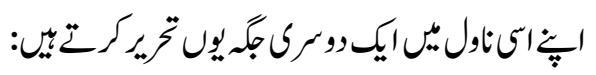

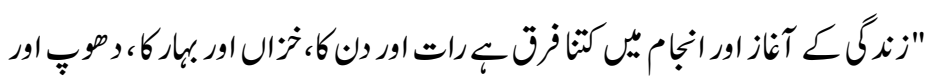

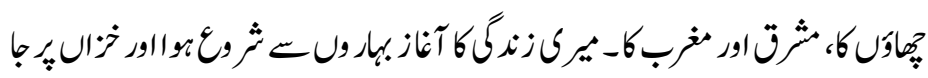

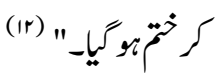

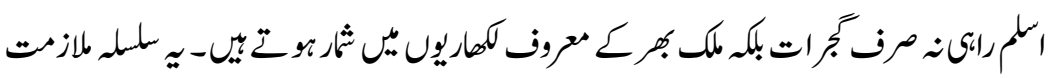

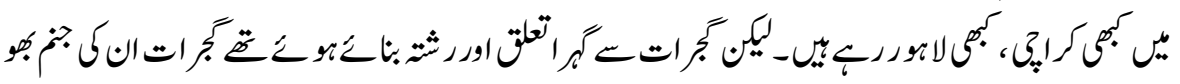

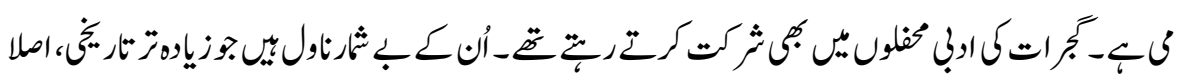

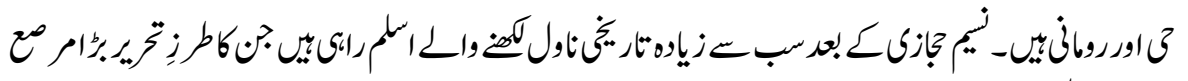

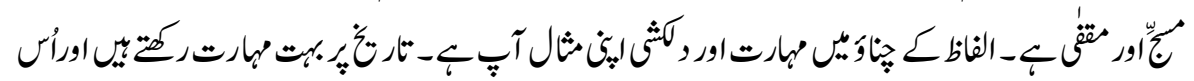

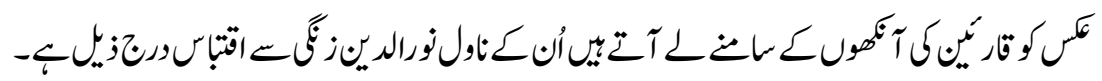

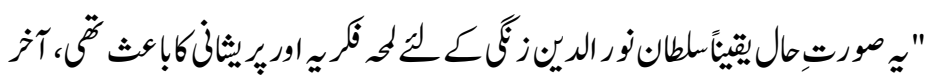

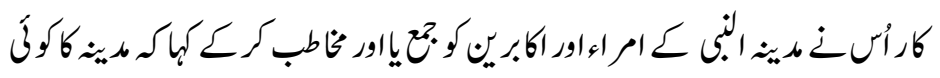

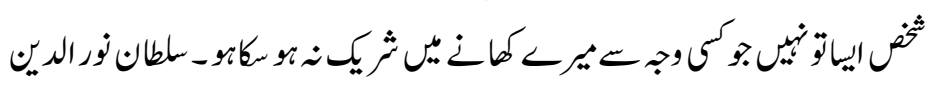

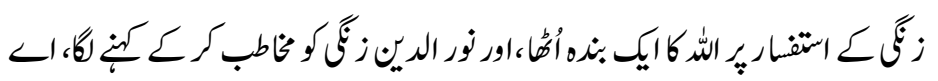

$\wedge 1$ 


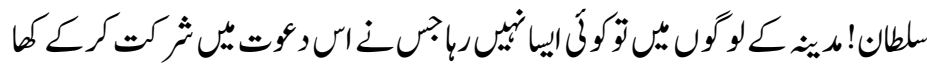

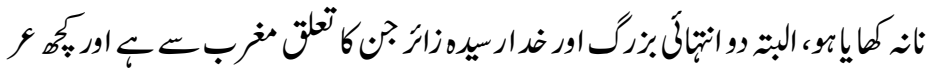

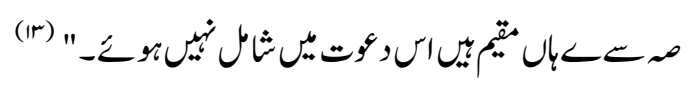

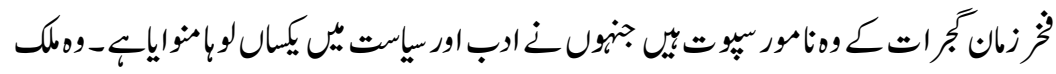

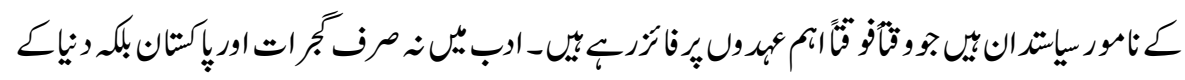

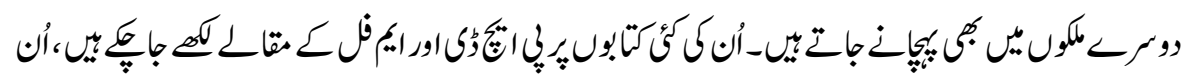

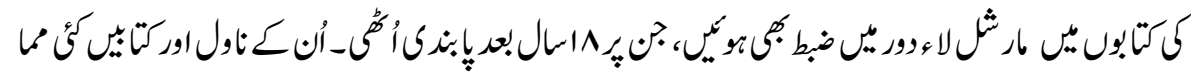

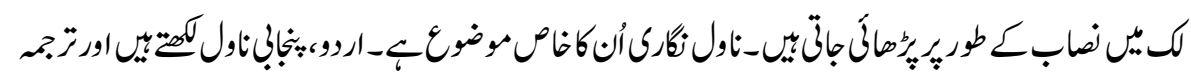

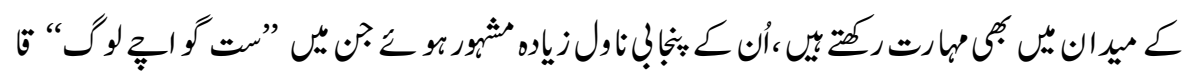

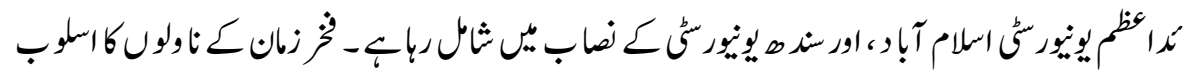

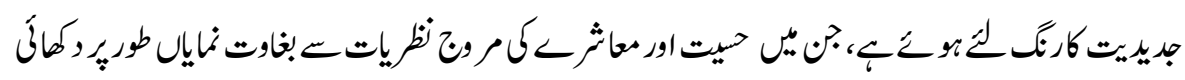

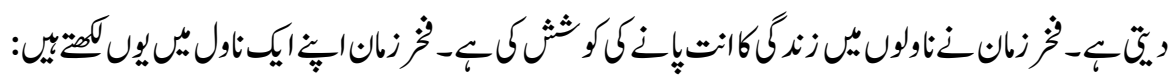

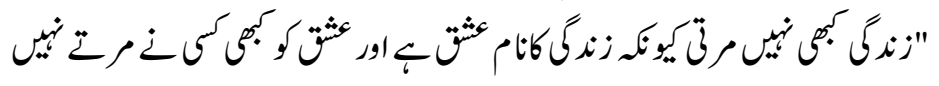

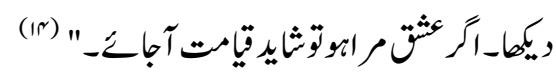

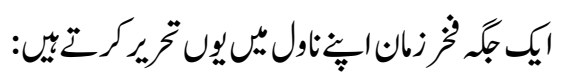

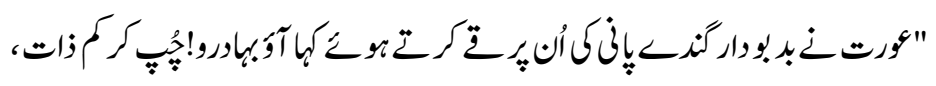

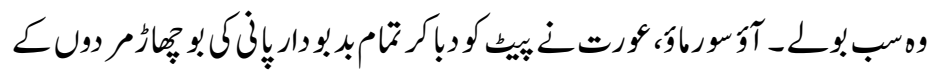

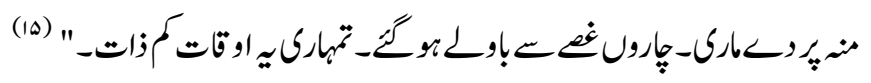

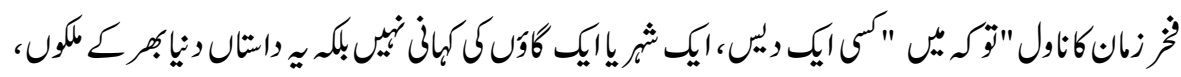

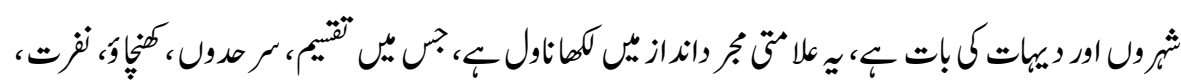

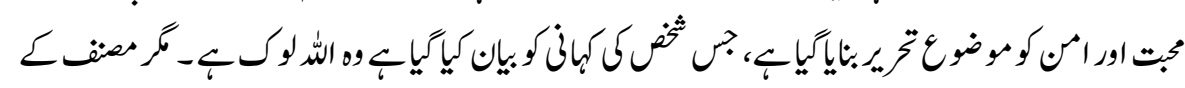

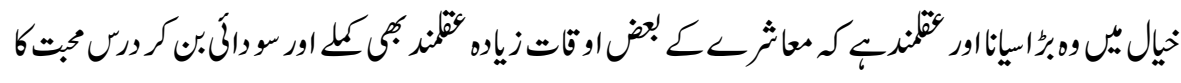

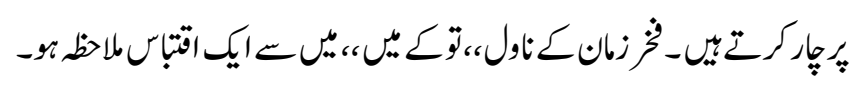




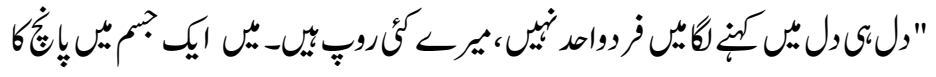

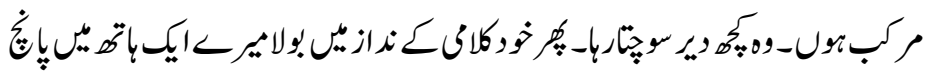

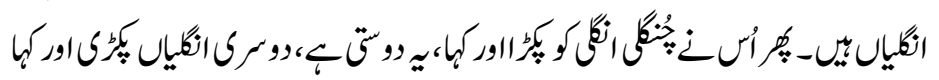

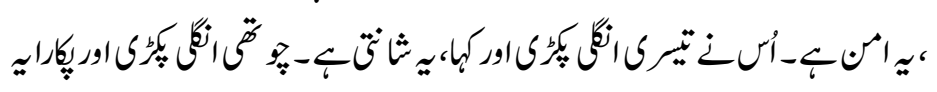

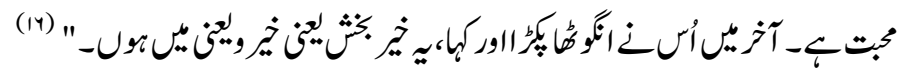

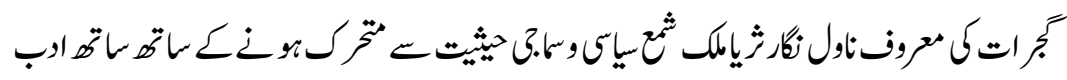

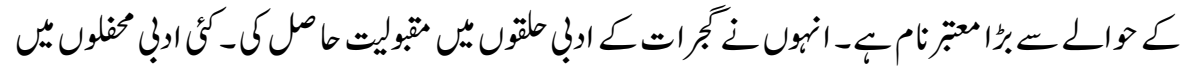

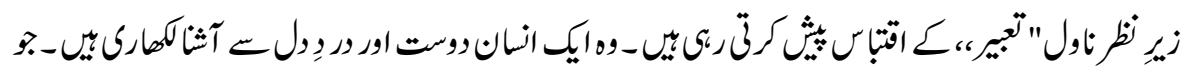

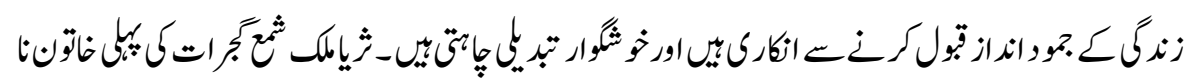

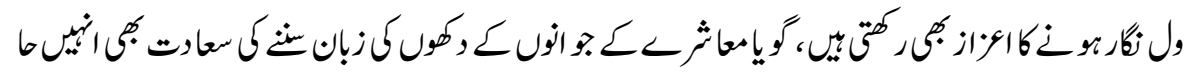

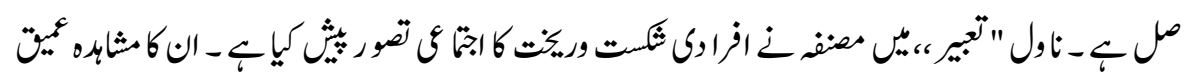

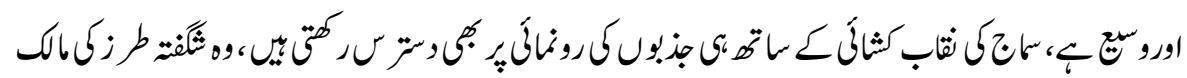

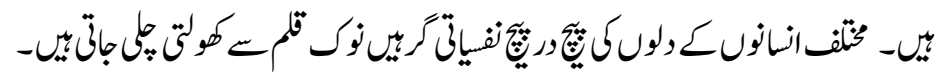

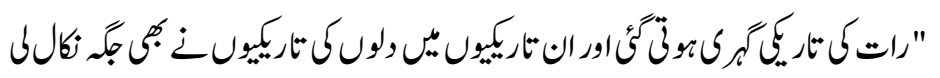

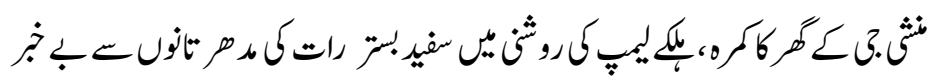

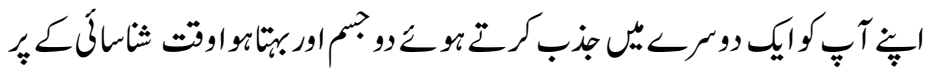

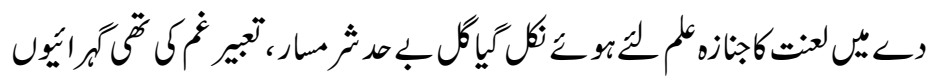

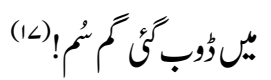

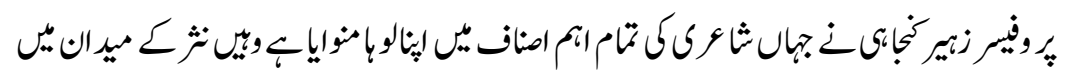

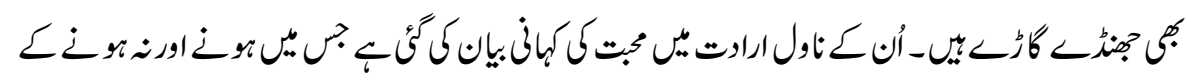

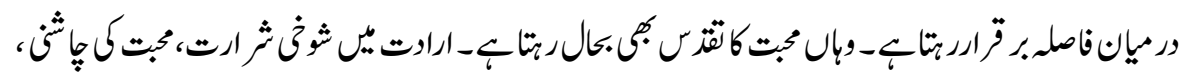

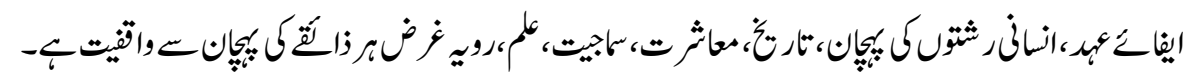




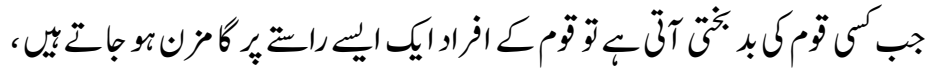

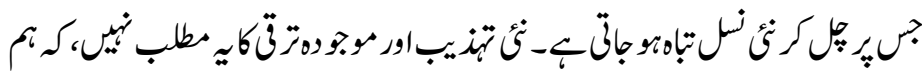

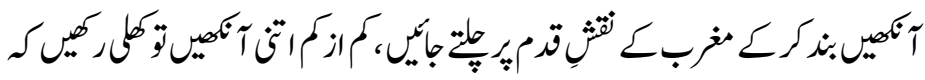

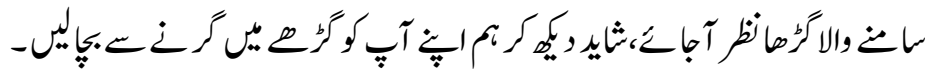

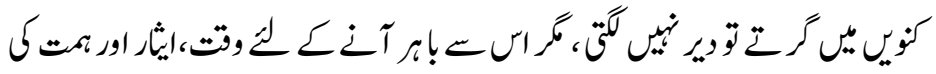

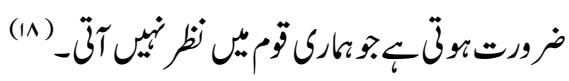

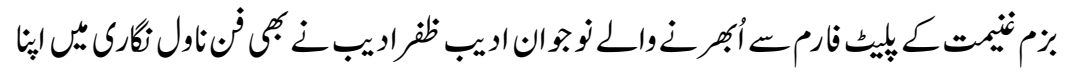

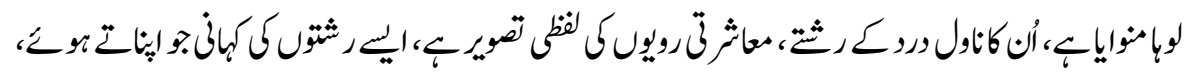

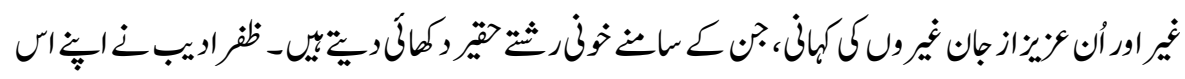

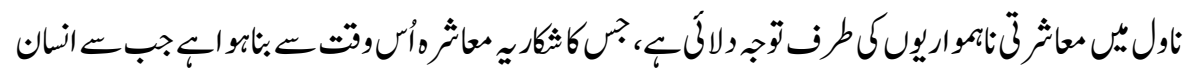

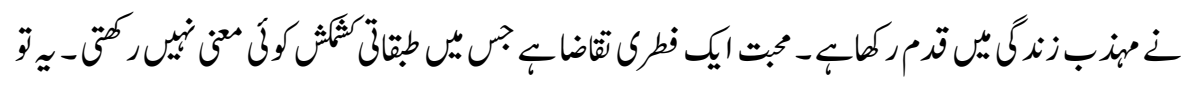

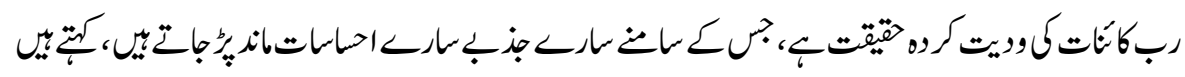

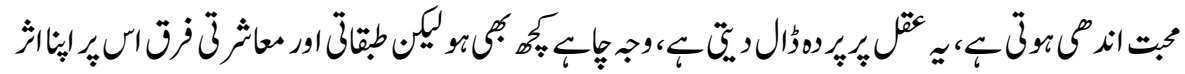

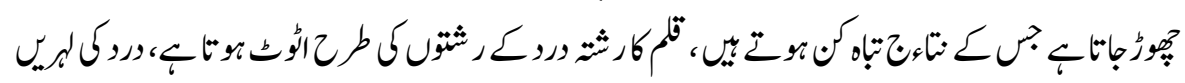

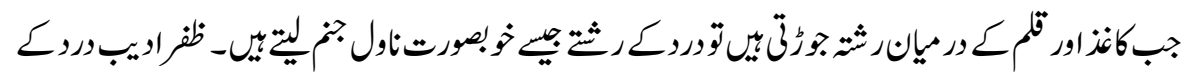

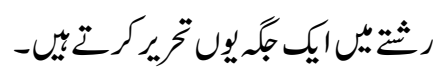

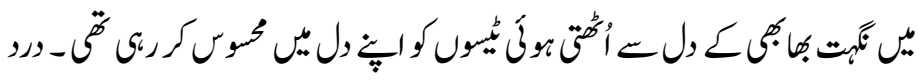

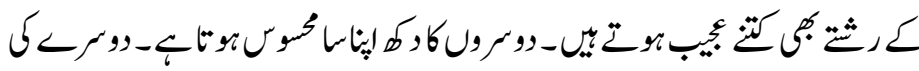

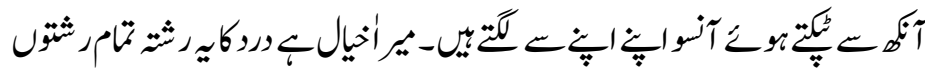

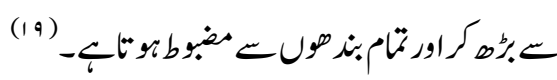

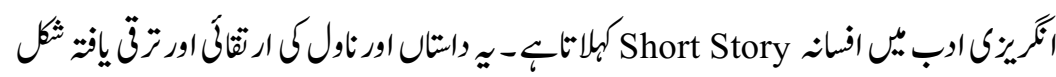

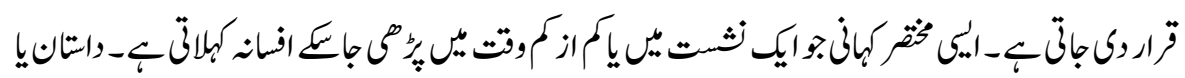

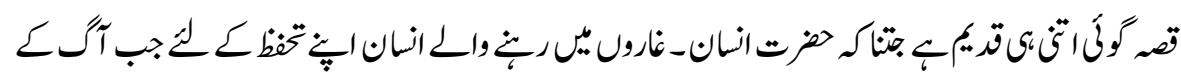


ISSN (Print): 2709-9636 | ISSN (Online): 2709-9644

Volume 2, 2021(Issue III, July to September)

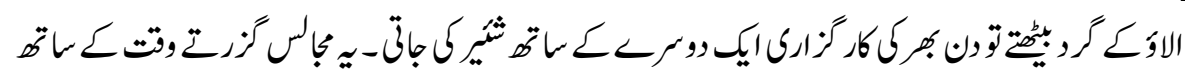

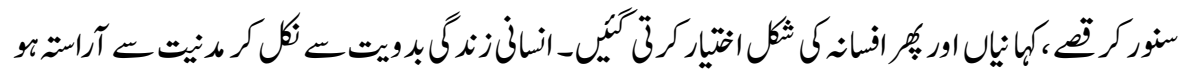

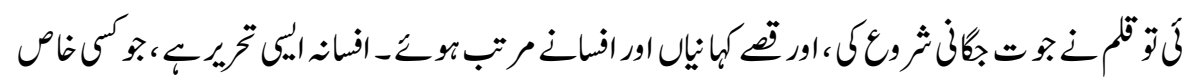

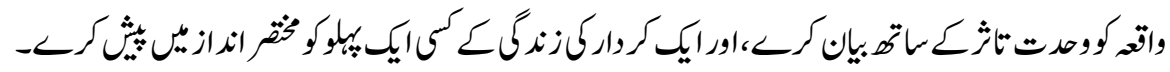

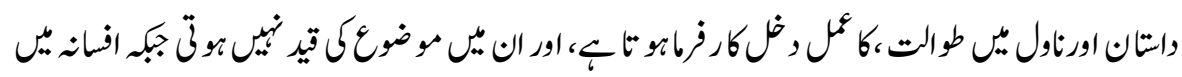

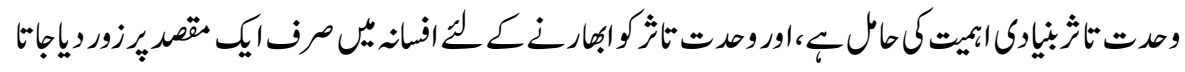

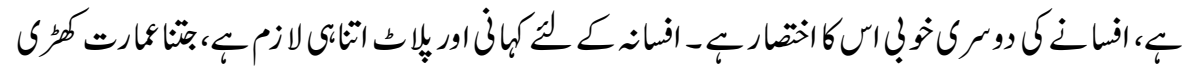

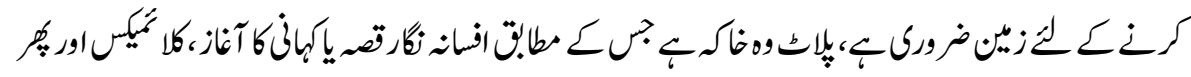

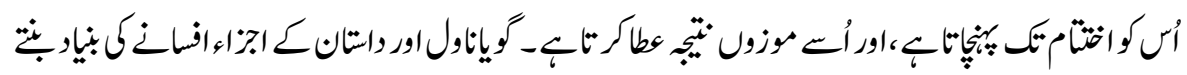

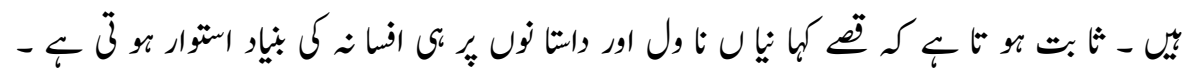

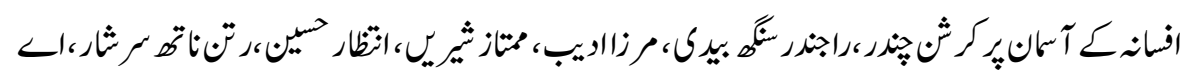

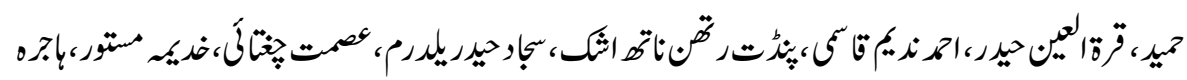

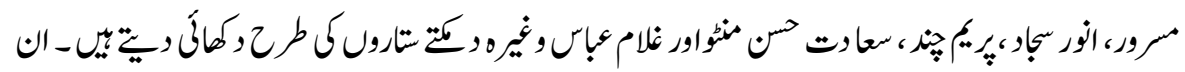

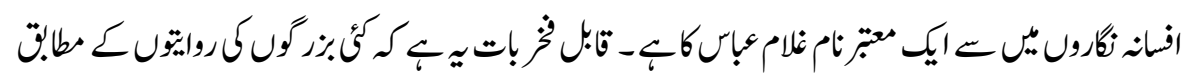

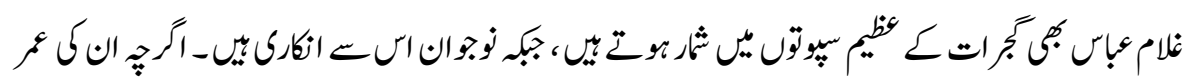

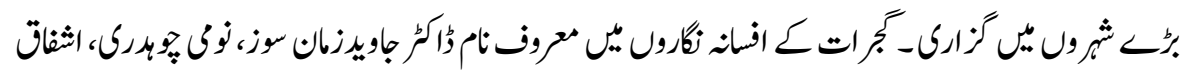

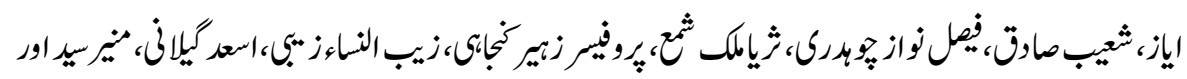

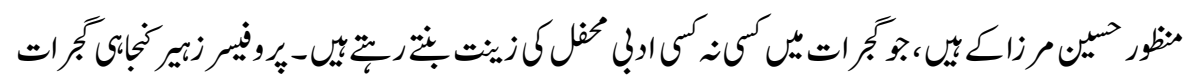

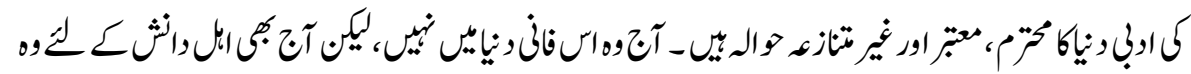

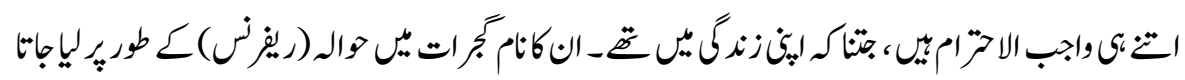

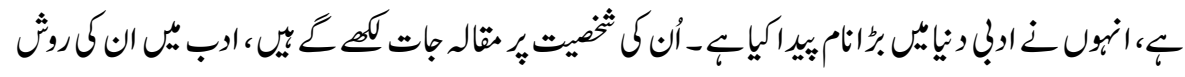

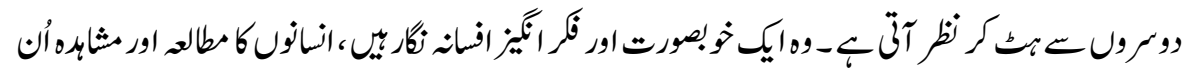

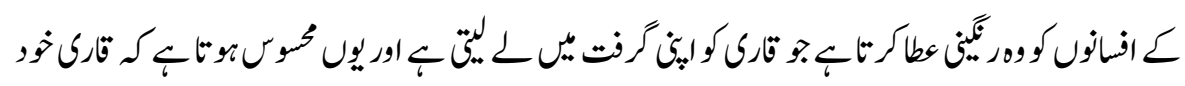


ISSN (Print): 2709-9636 | ISSN (Online): 2709-9644

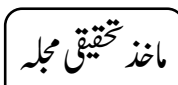

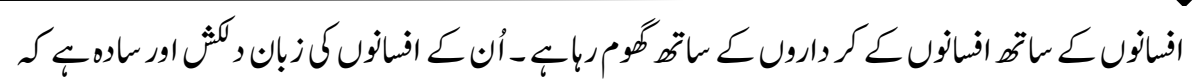

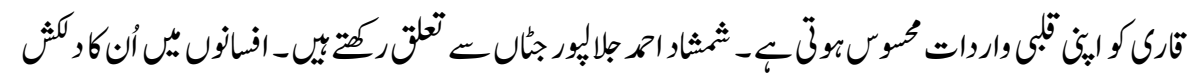

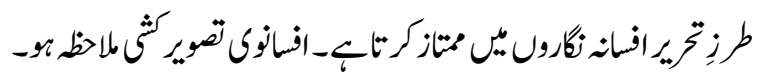

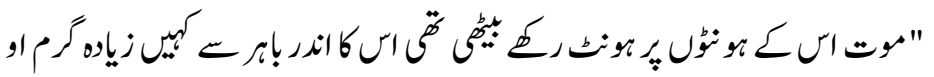

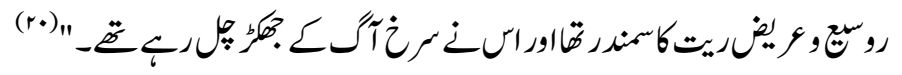

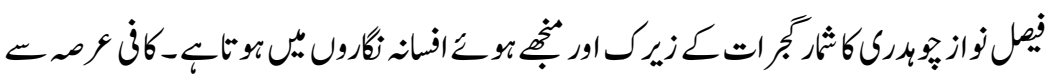

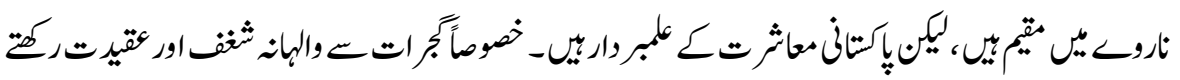

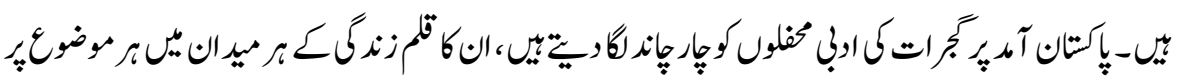

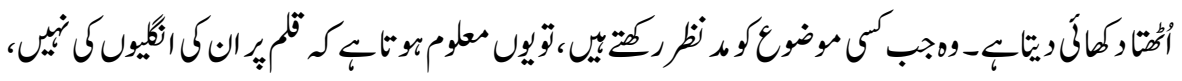

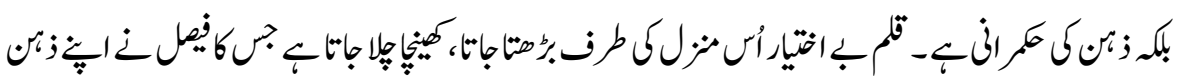

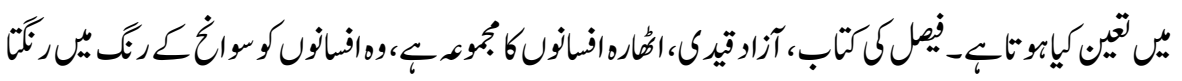

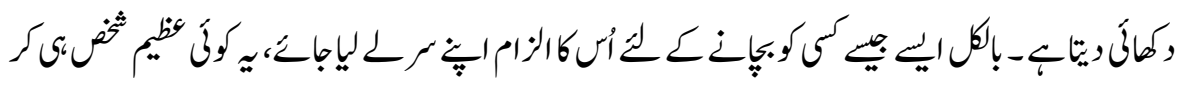

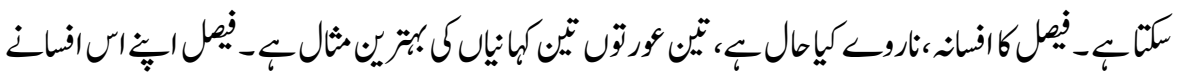

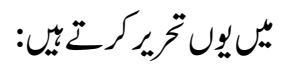

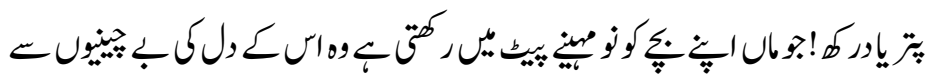

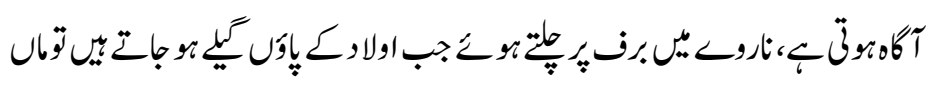

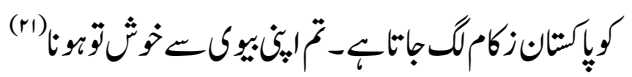

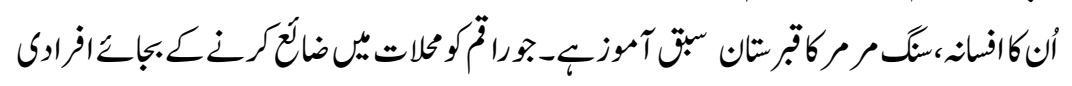

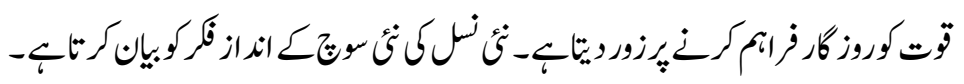

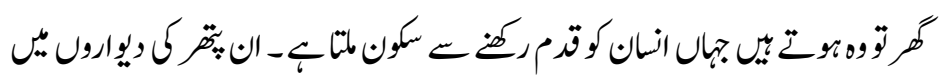

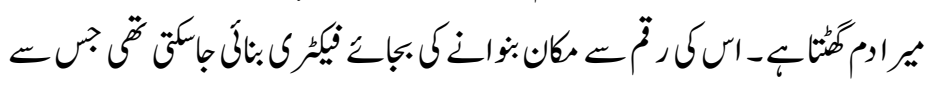

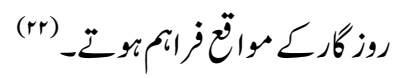


ISSN (Print): 2709-9636 | ISSN (Online): 2709-9644

Volume 2, 2021(Issue III, July to September)

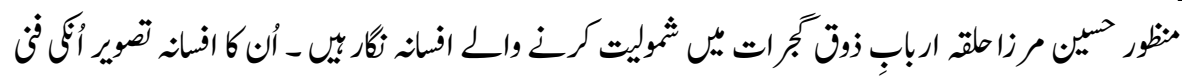

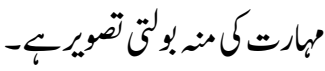

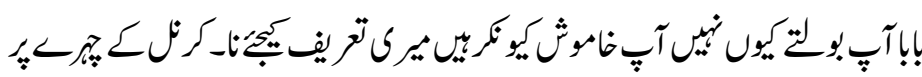

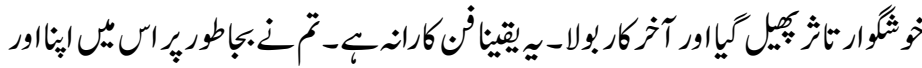

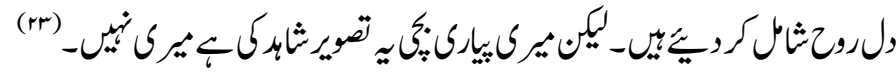

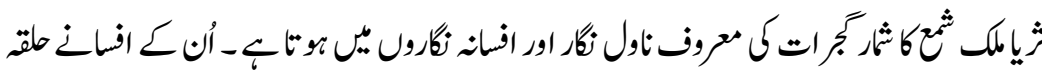

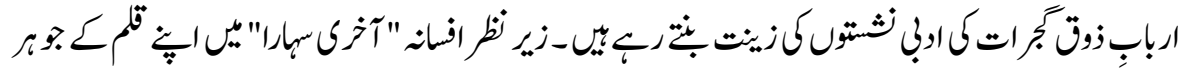

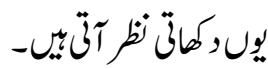

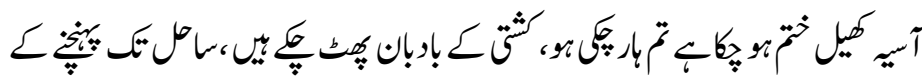

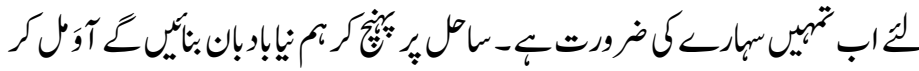

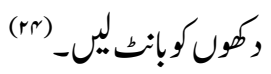

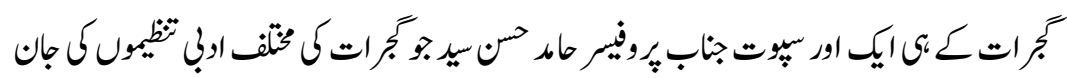

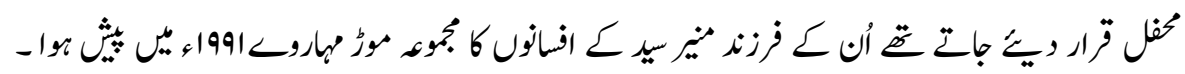

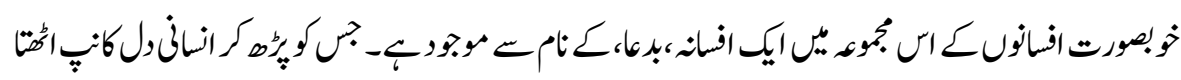

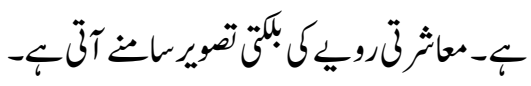

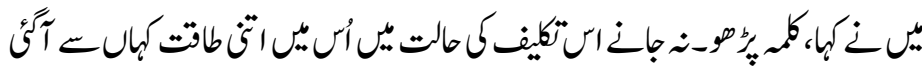

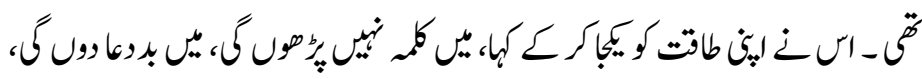

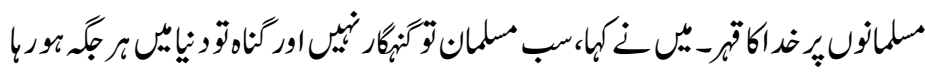

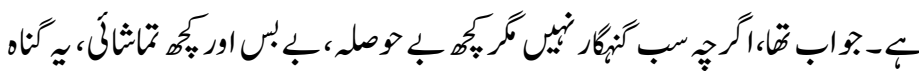

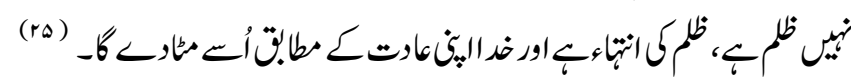

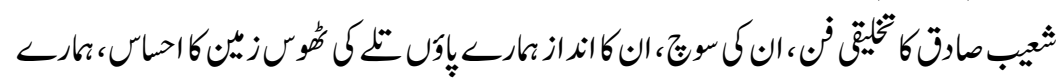

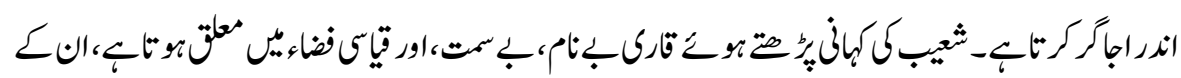


ISSN (Print): 2709-9636 | ISSN (Online): 2709-9644

Volume 2, 2021(Issue III, July to September)

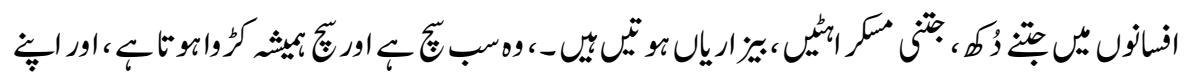

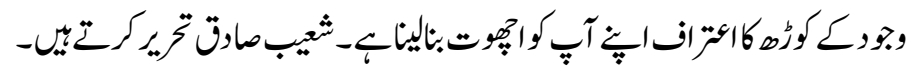

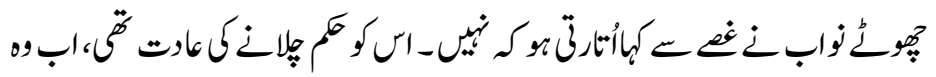

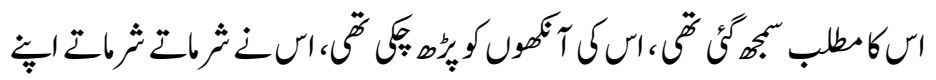

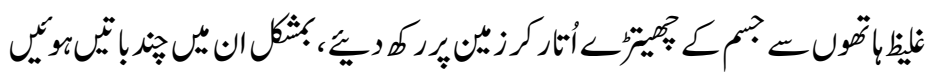

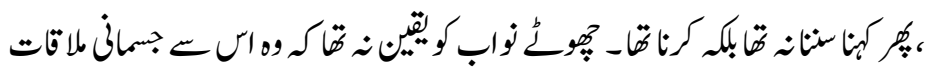

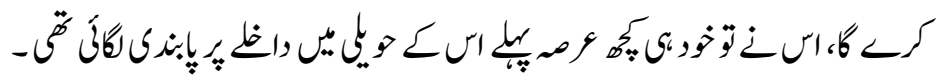

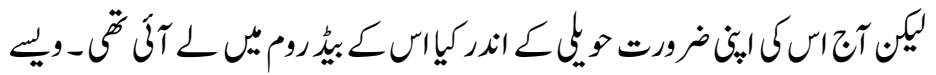

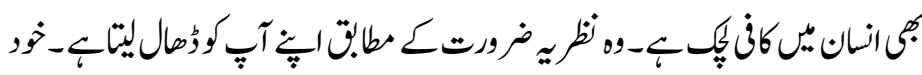

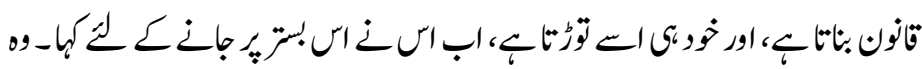

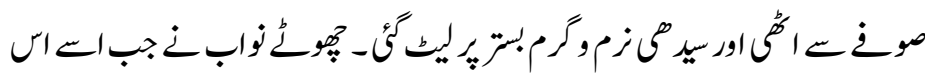

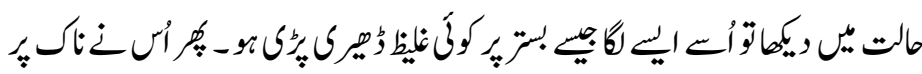

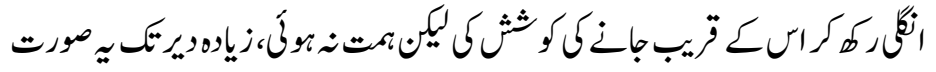

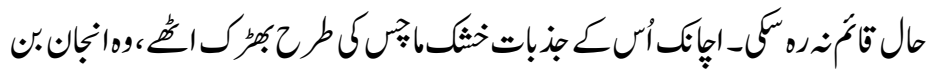

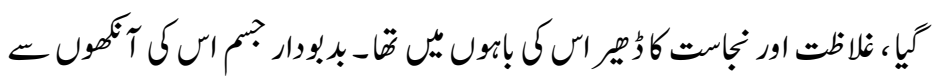

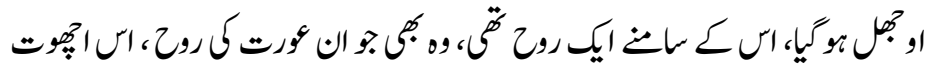

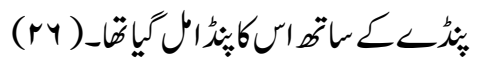

$$
\begin{aligned}
& \text { والرجات }
\end{aligned}
$$

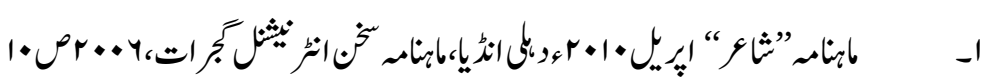

$$
\begin{aligned}
& \text { اليضاك، }
\end{aligned}
$$

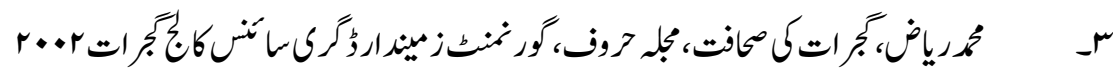

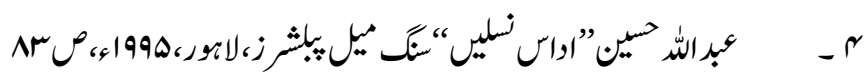


ISSN (Print): 2709-9636 | ISSN (Online): 2709-9644

Volume 2, 2021(Issue III, July to September)

اخذ تخيقي مجله

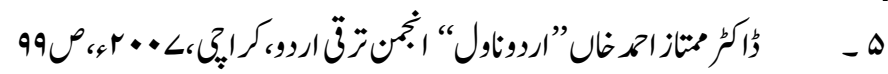

4

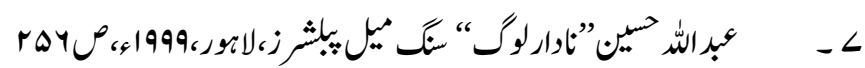

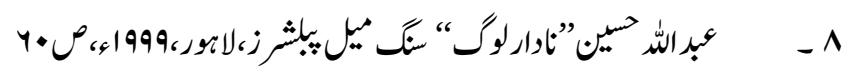

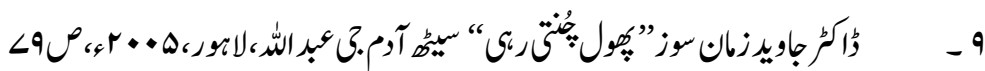

•

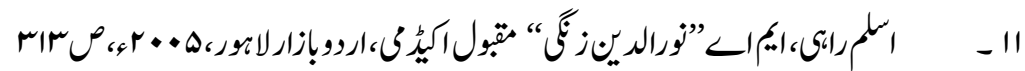

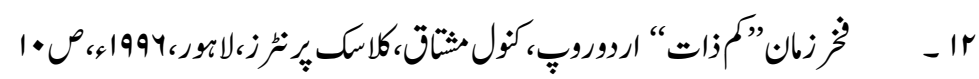

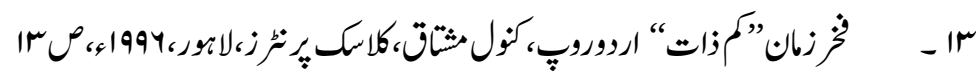

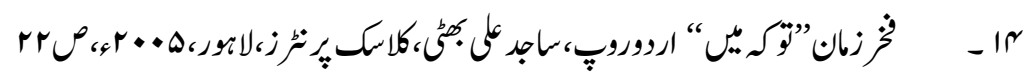

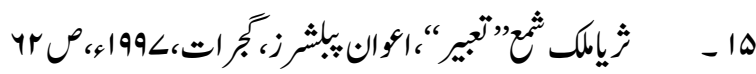

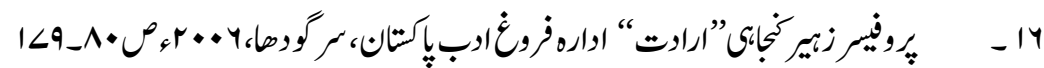

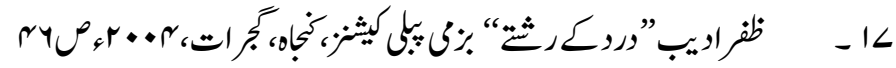

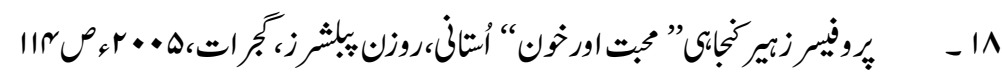

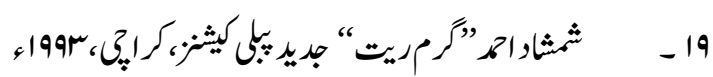

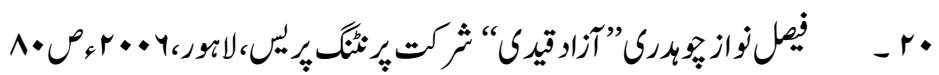

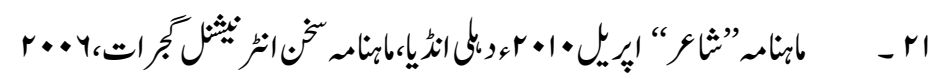

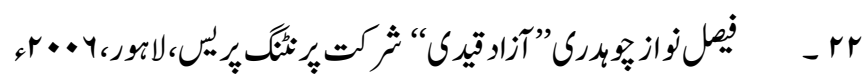

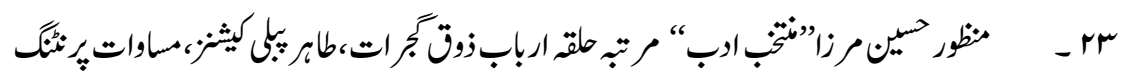

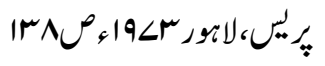

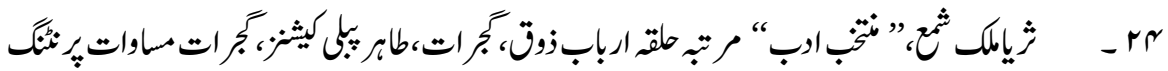




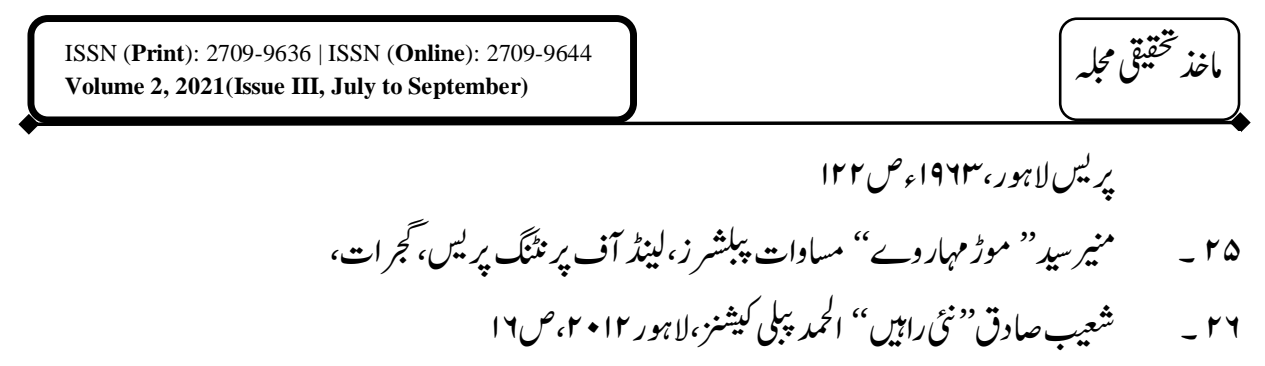

